\title{
MODELING THE BEHAVIOR OF METALLIC FAST REACTOR FUELS
} DURING EXTENDED TRANSIENTS*

by

ANL/RE/CP-77809

J. M. Kramer, Y. Y. Liu**, M. C. Billone** and H. C. Tsai**

DE93 002918

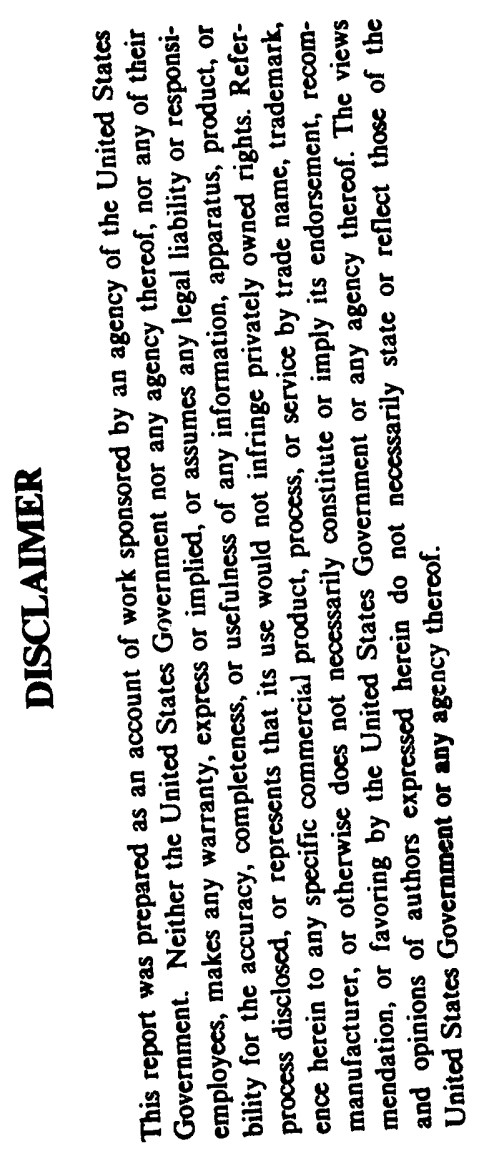

Reactor Engineering

**Materials and Components Technology Division

Argonne National Laboratory

9700 South Cass Avenue

Argonne, IL 60439 USA

Submitted to the ANS/ENS International Conference, November 15-20, 1992, Chicago, IL

* Work performed under the auspices of the U.S. Department of Energy.

Work supported by the U.S. Department of Energy under Contract W-31-109-Eng-38.

The submitted manuscript has been authored
by a contractor of the U. S. Government
under contract No. W-31-109-ENG-38.
Accordingly, the U.S. Government retains a
nonexclusive, royalty-free license to publish
or reproduce the published form of this
contribution, or allow others to do so, for
$U . S$. Government purposes.

U.

Submitted to the ANS/ENS International Conference, November 15-20, 1992, Chicago, IL

Work supported by the U.S. Department of Energy under Contract W-31-109-Eng-38. 


\title{
MODELING THE BEHAVIOR OF METALLIC FAST REACTOR FUELS DURING EXTENDED TRANSIENTS*
}

by

J. M. Kramer, Y. Y. Liu**, M. C. Billone** and H. C. Tsai**

\author{
Reactor Engineering \\ **Materials and Components Technology Division \\ Argonne National Laboratory \\ 9700 South Cass Avenue \\ Argonne, IL 60439 USA
}

\begin{abstract}
Passive safety features in the metal-fueled Integral Fast Reactor (IFR) make it possible to avoid core damage for extended time periods even when automatic scram systems fail to operate or heat removal systems are severely degraded. The time scale for these transients are intermediate between those that have traditionally been analyzed in fast reactor safety assessments and those of normal operation. Consequently, it has been necessary to validate models and computer codes (FPIN2 and LIFE-METAL) for application to this time regime. Results from out-of-reactor Whole Pin Furnace tests are being used for this purpose. Pretest predictions for tests FM-1 through FM-6 have been performed and calculations have been compared with the experimental measurements.
\end{abstract}

* Work performed under the auspices of the U.S. Department of Energy.

Work supported by the U.S. Department of Energy under Contract W-31-109-Eng-38. 


\section{Introduction}

The driver fuel for the Integral Fast Reactor (IFR) being developed by Argonne National Laboratory [1] is a metallic U-Pu-Zr alloy. One of the key features of metallic fast reactor fuels is improved safety through lower stored energy and enhancements in the negative reactivity feedback during off-normal events [2]. As a consequence of these characteristics it is possible to avoid core damage even for circumstances where the automatic scram system fails to operate or heat removal systems are severely degraded. During such transients the reactor slowly heats up over tens of minutes to hours until the overall negative reactivity feedback and/or decreasing decay heat brings the reacior power into equilibrium with the available heat rejection rate [3]. The time scales for these extended transients are intermediate between those of the accident transients that have traditionally been analyzed in fast reactor safety assessments and those of normal operation. Consequently, it has been necessary to validate models and computer codes (FPIN2 and LIFE-METAL) for application to analyses of metallic fuel in this intermediate time regime. The subject of the present paper is the modeling of the behavior of metallic fuels during extended transients and the validation of the models using the results of recent Whole Pin Furnace tests on irradiated fuel pins.

\section{The transient behavior of metallic fast reactor fuels}

\section{$2.1 \quad$ IFR fuel}

The IFR fuel is a U-xPu-10Zr metal alloy, where the Pu weight fraction $\mathrm{x}$ depends on the reactor application. For example, in the current PRISM reactor design [4] $x=0$ for the blankets and $\mathrm{x}=26-28$ for the driver fuel; whereas $\mathrm{x}=20$ for the planned conversion of Argonne's EBR-II reactor to the Mark-V driver fuel. The reference cladding for both of these applications is the low swelling ferritic/martensitic alloy HT9 (ASME Specification S42100; nominally Fe-12Cr-1Mo). 


\subsection{Transient time regimes}

Fast reactor safety issues related to fuel behavior center around cladding integrity, fuel motion reactivity feedback and core coolability. Here we will concentrate on cladding integrity, which is of fundamental concern because the cladding provides the primary barrier to the release of radionuclides.

Cladding damage during accident transients is a strong function of cladding temperature. Figure 1 shows representative peak cladding temperature histories for various accident transients. Although the curves are for the SAFR $900 \mathrm{MWt}$ design [5], the overall time scales of the temperature regimes e representative of the general response of an IFR metal-fueled fast reactor. The Design Basis Accident (DBA) transients shown in the figure include scram-protected Transient Overpower (TOP), Loss-Of-Flow (LOF) and Loss-Of-Heat Sink (LOHS) events. The thermal response of the cladding for these transients can generally be characterized by a temperature ramp of $1-100^{\circ} \mathrm{C} / \mathrm{s}$ followed by reactor scram and rapid cooling within 10-20 s after accident initiation. A second class of transients shown in the figure are the Anticipated Transient Without Scram (ATWS) events. The ATWS events have some of the same initiators as the DBA transients, but are of lower probability because the automatic reactor scram system is assumed to fail. The cladding temperatures for these extended transient events increase until about $50 \mathrm{~s}$, at which point passive reactivity feedbacks from the core expansion stabilize the system at slightly elevated temperature after 100-1000 s. In the longer term (tens of hours) the cladding temperatures depend on the availability of the Shutdown Heat Removal System (SHRS). The primary method of removing decay heat is with the steam generator [2]. However, passive backup systems are provided in case the steam generator is not available. The final set of curves shown in Fig. 1 illustrate cladding temperatlire histories when various combinations of the three decay heat removal systems in the SAFR design were assumed to be unavailable until 10 hours after reactor shutdown. Times in the range of 10-36 hours are generally regarded as sufficient for operator intervention to bring one of the systems into at least partial operation.

\section{$2.3 \quad$ Fuel pin damage}

Assessments of IFR safety must be capable of analyzing the response of the fuel pins over the broad range of accident transients illustrated in Fig. 1. Damage to the cladding in metallic fuel pins during such transients can be produced by mechanical loading and by metallurgical interaction 
with the fuel. The primary sources of mechanical loading come from fission gas plenum pressure and Fuel-Cladding Mechanical Interaction (FCMI) [6]. Gas pressure loading is dominant for low burnup fuel where the fuel-cladding gap has not closed and for undercooling transients where the cladding tends to expand away from the fuel. FCMI loading of the cladding can occur under transient overpower conditions where the fuel expands into the cladding. However, certain characteristics of metallic fuels tend to minimize this effect. These characteristics include the similarities in thermal expansion coefficients between the fuel and the cladding, the high conductivity of the fuel which reduces the temperature differences between the fuel and the cladding, and the compliance provided by the fuel porosity. In addition, the greatest transient cladding damage usually occurs at the axial location where the cladding temperatures are greatest. In metallic fuel pins this occurs near the top of the fuel column where the fuel stresses tend to relax to a hydrostatic state in equilibrium with the plenum pressure .

Fuel-cladding metallurgical interaction is another important source for cladding damage in metallic fuels. Damage during normal operation is caused by the interdiffusion of fuel constituents and lanthanide fission products with the cladding constituents. This can cause brittle zones in the cladding which, for modeling purposes, are assumed to be part of the cladding wastage. In addition, at the elevated temperatures of accident transients liquefaction at the fuel-cladding interface can occur above a certain threshold temperature. This threshold temperature is related to the eutectic that forms in the uranium-iron system at $715^{\circ} \mathrm{C}$. Addition of zirconium to the fuel tends to increase the threshold temperature whereas plutonium and lanthanide fission products tend to decrease the temperature. From the siandpoint of accident transients, the most important factor is the accelerated rate of cladding attack once eutectic liquefaction occurs at the interface. The cladding penetration rate appears to obey an Arrhenius temperature dependence for temperatures between the liquefaction threshold and $1080^{\circ} \mathrm{C}$. Above $1080^{\circ} \mathrm{C}$ the rate accelerates by several orders of magnitude such that cladding failure becomes essentially instantaneous [7]. One of the active tasks in the IFR program at Argonne is the measurement of cladding attack as a function of fuel type, cladding type, fuel burnup and irradiation temperature [8]. These tests are being performed in the Fuel Behavior Test Apparatus (FBTA) in which small samples of irradiated fuel are heated inside of a radiant furnace.

In modeling the transient damage to metallic fuel pins the cladding loads are assumed to be carried by the cladding tendon unaffected by wastage. The calculated deformation and failure of this 
tendon relies on models based on mechanical properties measurements. A key concern in applying these models to extended transients is the applicability of the models to the time and temperature regimes of interest. This is of particular concern for HT9 cladding because changes in the microstructure of this material can occur during high temperature service. One of the manifestations of these changes is the apparent strengthening of the alloy with time, possibly due to secondary carbide precipitation [9]. A graphic illustration of the importance of this phenomenon to fuel pin behavior analyses is shown in Fig. 2. Cladding rupture times from Fuel Cladding Transient Tester (FCTT) experiments [10] performed at different heating rates are plotted as a function of time and temperature using a Dorn parameter $\Theta$ with an activation energy of $70.2 \mathrm{kcal} /$ mole to reduce the data to one curve. However, when longer term creep data at $650^{\circ} \mathrm{C}$ are plotted on the same figure, the data diverge from the master curve for longer times (shown on the upper scale). The full extent of this divergence is illustrated by adding creep data at other temperatures to the $650^{\circ} \mathrm{C}$ data using a second Dorn parameter with an activation energy of $154 \mathrm{kcal} / \mathrm{mole}$ to bring all of the creep data into coincidence. For a typical cladding stress of $100 \mathrm{MPa}$, for instance, the short-time master curve would predict cladding failure after 11 hours at $650^{\circ} \mathrm{C}$, whereas the long-time master curve would not indicate failure until 360 hrs. A similar discrepancy between the long-time and short-time mechanical behavior of HT9 cladding also occurs in the plastic flow behavior, with the creeping material displaying much greater strength than would be indicated by extrapolation short-term tensile data [9]. These discrepancies are important to the LIFE-METAL and FPIN2 calculations discussed later in this paper because cladding plastic strain and the Cumulative Damage Fraction (CDF) are the two primary cladding failure crite 1 ia used in the codes. This latter criterion is based on correlations of the cladding rupture data shown in Fig. 2 in conjunction with the cumulative damage fraction rule

$$
C D F=\int_{0}^{t} \frac{d t}{t_{r}(\sigma, T)}
$$

where $T$ is the calculated temperature history, $\sigma$ is the calculated stress history and $t_{r}$ is the rupture time at constant stress and temperature as determined from the correlation of the cladding rupture data. For consistency with the underlying data, the expected value of the CDF at the predicted failure time $t$ is 1.0 . 


\subsection{Transient test regimes}

One of the key phases in the development of models and codes for analyzing IFR fuel behavior is the validation of these tools through comparison of calculated results with the results of experiments on metallic fuels. Validation of individual models contained within the codes is usually achieved by using separate effects experiments, whereas overall validation of the codes is achieved through comparisons with integral experiments on intact fuel pins. Examples of the separate effects experiments are the FCTT transient cladding burst tests and the FBTA fuel-cladding compatibility tests mentioned above. Tests on intact fuel pins include in-reactor tests in the TREAT and EBR-II reactors, and out-of-reactor Whole Pin Furnace tests.

\subsection{TREAT tests}

The only way to achieve fully-prototypical transient testing of IFR fuel pins is to use inreactor nuclear heating with flowing sodium. The TREAT reactor is being used by the IFR program to provide such data for short-term transients. The tests that have been run thus far, designated M2-M7, have been TOP simulations with an exponential period of $8 \mathrm{~s}$ [11]. A primary aim of these experiments has been to study the margin to cladding failure by continuing the overpower ramp until failure occurred. However, although the TREAT tests provide valuable short-term data for model validation, they cannot continue the transients beyond about 10-20 s because the TREAT energy deposition is limited to a few tens of full power seconds. One of the consequences of this limitation is to force the cladding failures to less prototypical conditions where the cladding temperatures exceed the $\alpha-\gamma$ phase transformation temperature for HT9 $\left(840^{\circ} \mathrm{C}\right)$ and where the failure tends to be dominated by the onset of rapid eutectic penetration $\left(1080^{\circ} \mathrm{C}\right)$. In addition, the times are too short to observe any strengthening effects of microstructural changes in the cladding that may occur during extended transients.

\subsection{EBR-II tests}

The EBR-II reactor is providing the bulk of the irradiation performance data for IFR metallic fuels. This data is being used to validate models for the long-term behavior of metallic fuel pins. The data include fuel restructuring, fission gas release, fuel growth, cladding deformation and 
cladding lifetime. Slow ramp-rate transient overpower tests are also being performed in EBR-II. These tests will help resolve issues related to Fuel Cladding Mechanical Interaction under slower heating conditions than those used in the TREAT tests. However, the majority of the EBR-II data comes from the steady-state irradiation performance program where the peak cladding temperatures are lower $\left(550-660^{\circ} \mathrm{C}\right)$ and times are longer (years) than those of interest during the extended transients shown in Fig. 1.

\subsection{Whole Pin Furnace tests}

The Whole Pin Furnace (WPF) testing facility [12], located in the Alpha-Gamma Hot Cell Facility at Argonne, has been developed to span the range between the TREAT and the EBR-II test regimes. This facility uses a computer-controlled radiant furnace which is able to heat intact irradiated fuel pins to the point of cladding breach. The practical capabilities of the WPF system are heating rates up to $30^{\circ} \mathrm{C} / \mathrm{s}$ and a peak temperature of $1100^{\circ} \mathrm{C}$ for times up to several days. A comparison of these characteristics with Fig. 1 shows that the WPF test regime covers the range of extended transients that are the subject of this paper. It is also important to note that, with the exception of the unprotected TOP event, the reactor power for all of the other events shown in Fig. 2 is at or near decay heat levels after the first $50-100 \mathrm{~s}$. This fact in combination with the high thermal conductivity of metallic fuels means that temperature profiles with the external heating in the WPF tests can nearly match those of the accident transient being simulated.

\subsection{IFR Fuel pin behavior codes}

The LIFE-METAL [13] and FPIN2 [14] computer codes have been developed to model the thermal and mechanical behavior of IFR metallic fuel pins. The LIFE-METAL code was developed primarily for the analysis of the behavior of metallic fuel pins under normal operating conditions, while FPIN2 was developed to analyze the behavior under accident transient conditions. Although there is some overlap in capabilities for handling operational transients, such as reactor start-up and shut-down, the emphasis in the development and validation of the codes has been very different. LIFE-METAL has concentrated on models which describe steady-state irradiation performance, using EBR-II irradiation data to validate the code. On the other hand, FPIN2 incorporates models relevant to the time scale and temperature range of accident transients, but requires the user to provide data 
describing the pretransient condition of the fuel pin. FPIN2 has relied on TREAT tests as the primary source of data for overall code validation. Because the regime of extended transients requires an extrapolation for both codes (LIFE-METAL to shorter times and FPIN2 to longer times), both have been applied to pretest analyses of the Whole Pin Furnace tests discussed in Section 5.0.

In spite of the differences in the models in the LIFE-METAL and FPIN2, there are many similarities in the fundamental assumptions that determine the governing equations that are solved. For instance, both codes use a finite difference formulation of the heat transfer which assumes that heat is only conducted radially in the fuel and the cladding and convected axially by the coolant. For the purpose of analyses of experiments such as the Whole Pin Furnace tests, options are available to bypass the coolant calculation and input directly the known cladding surface temperatures. The mechanical analyses in both codes assume axial symmetry and generalized plane strain which results in an essentially one-dimensional (radial) calculation for each axial node of the fuel pin. LIFEMETAL uses a finite difference formulation of the governing equations whereas FPIN2 uses a finite element formulation. In addition, both codes use the fundamental properties of metallic fuel pins from the Metallic Fuels Handbook that has been compiled by the IFR project.

As mentioned above, differences in the regimes that the LIFE-METAL and FPIN2 address have resulted in major differences in the models contained within the codes. To some extent these differences have also influenced the formulation of the equations and solution procedures (eg. finite difference vs finite element). One ( $f$ the differences in modeling that most affects the calculations presented in the following section is the modeling of the deformation and failure of HT9 cladding. Here LIFE-METAL has based the models on long-term creep tests, while FPIN2 has based the models on tensile test data and the FCTT data.

\subsection{Analyses of the Whole Pin Furnace Tests}

Six Whole Pin Furnace tests have been conducted using IFR metailic fuel pins irradiated in EBR-II. Key pin parameters and test conditions are summarized in Table 1. The LIFE-METAL and FPIN2 results presented below are predictions made before each test was carried out. 
Both LIFE-METAL and FPIN2 used the pretransient characterization (geometry, fission gas release, fuel restructuring, etc.) for each of the test pins provided by LIFE-METAL analyses of the irradiation of the pins in EBR-II. This was done to minimize the influence of the assumed pretransient condition of the pins on the comparisons of the code predictions for the tests. Both codes also input the same cladding surface temperatures based on the planned peak cladding temperature and the axial temperature profile determined from measured furnace characteristics.

LIFE-METAL and FPIN2 provide detailed information on fuel pin temperatures, stresses, deformation and damage at the radial and axial nodes of the computational meshes. However, only certain results are relevant for comparisons with experimental data. For the WPF tests these include the cladding failure time, the peak cladding plastic strain and the extent of eutectic liquid attack of the cladding. Table 2 compares the predicted values of these parameters with the measurements from the tests. It should be noted here that the calculated plastic strain and cladding attack are given for the predicted location and time of failure (or test termination time for pins that were not predicted to fail).

The calculated cladding failure times given in Table 2 are based on various failure criteria contained within the codes. The transient CDF criterion and $6 \%$ cladding strain criterion are based on data from the FCTT transient tube burst tests discussed in Section 2.2. Similarly, the steady-state $\mathrm{CDF}$ and $2 \%$ plastic strain criteria are based on the long-term creep-rupture data.

\subsection{Tests FM-1 through FM-3}

Tests FM-1 through FM-4 were ramp-and-hold tests with the peak-cladding temperature ramped from $500^{\circ} \mathrm{C}$ to the test temperature at $6^{\circ} \mathrm{C} / \mathrm{s}$, followed by a iold at the test temperature until fuel pin failure was detected. The principal variables in these tests were the plutonium content in the fuel, the ratio of the plenum volume to fuel volume and the peak fuel burnup.

The LIFE-METAL FM-1 calculation using the steady-state CDF gave an unrealistically short failure time of $8.2 \mathrm{~s}$. This was anticipated because the application of the steady-state CDF to the time and temperature regime of test FM-1 requires a considrrable extrapolation of the long-term stress rupture data. The calculations were therefore repeated using the transient CDF correlation in the 
code. This correlation predicts longer failure times than the steady-state correlation for higher temperatures, but shorter failure times for lower temperatures. The crossover in predicted failure times is caused by the much larger activation energy for the creep rupture data in comparison to the transient FCTT rupture data. The LIFE-METAL predictions using the transient CDF are in reasonable agreement with the test results given in Table 2 for tests FM-1, FM-2 and FM-3. Also in agreement with the data, eutectic penetration was a primary contributor to the failure of the low burnup pins used in these tests, with about $50 \%$ of the cladding wall consumed prior to failure.

The FPIN2 predictions for tests FM-1 and FM-2 produced the unexpected result that plastic instability of the cladding in the long uniformly-heated zone of the test section would create sufficient volume to rapidly decrease the plenum pressure near the end of the tests. This caused very large uniform plastic strains to accumulate well before the CDF reached 1.0. Such behavior was judged to be unrealistic because any instability would tend to localize in the form of a bulge. In subsequent calculations plastic instability was suppressed by using the small strain option in the code. This allowed the calculations to continue beyond the point of plastic instability.

The FPIN2 calculations given in Table 1 are also in reasonable agreement with the measurements from the first three WPF tests. In general FPIN2 predicted shorter failure times and larger plastic strains than LIFE-METAL with the two sets of calculations bracketing the experimental results. Much of the difference between the code predictions is attributable to the differences in the models for the mechanical deformation of HT9. An additional factor was that the FPIN2 calculations used the nominal correlation [6] for eutectic penetration rate whereas LIFE-METAL used a somewhat slower rate based on FBTA tests on sibling pins.

With regard to the level of agreement between calculated and measured failure times, it should be noted that the HT9 rupture data and eutectic penetration rate data have considerable scatter which contributes to uncertainties in model parameters. An independent assessment of these uncertainties suggests that one should not expect better agreement in time to failure than about a factor of 2 . 
Test FM-4 [15] was also a ramp-and-hold test, but the fuel burnup and plenum pressure were much higher than in the previous tests. Because of this, and because of the lower test temperature, the mode of pin failure was calculated to be mechanical deformation of the cladding with minimal eutectic thinning. This is in general agreement with the results given in Table 2. However, both LIFE-METAL and FPIN2 predicted much shorter failure times than were m.aasured. Part of the explanation for shorter times is that the pretest calculations used $780^{\circ} \mathrm{C}$ for the peak cladding temperature, whereas $770^{\circ} \mathrm{C}$ was measured in the test. In additir $\mathrm{n}$, the large plastic strains that were measured in the plenum $(\sim 15 \%)$ were sufficient to reduce the plenum pressure more than calculated. These strains may also have caused some contact between the fuel pin and the capsule wall in the test section, thereby adding to the structural rigidity of the cladding.

\subsection{Test FM-5}

Test FM-5 [15] was conducted as a proof test to demonstrate that fuel similar to the EBR-II Mark-V driver fuel can endure the most severe EBR-II DBA (the UN-1 LOF event) with only minor incremental cladding strain and wastage, and no cladding breach. The FM-5 thermal transient was designed to effectively envelope the UN-1 cladding temperature history over the time that transient cladding damage would be expected to occur, as shown in Fig. 3. Only FPIN2 computations were performed for this test. The summary results of the calculations are given in Table 2. The peak transient CDF, cladding plastic strain and eutectic penetration at the top of the fuel column only reached $3 \%, 0.6 \%$ and $0.15 \%$, respectively. These results are consistent with the experimental observations which indicate that the EBR-II Mark-V fuel can endure the UN-1 event with minimal fuel pin damage.

\subsection{Test FM-6}

Test FM-6 was run as a two stage ramp-and-hold test at a nominal cladding temperatures of $650-670^{\circ} \mathrm{C}\left(650^{\circ} \mathrm{C}\right.$ at the fuel top, $670^{\circ} \mathrm{C}$ in the plenum $)$. Stage 1 of the test was run for 12 hours, after which the pin was removed from the test section to measure the incremental diametral strains. The pin was then inserted back into the furnace and run for another 24 hours. One of the purposes 
for conducting the test in this manner was to provide additional information concerning the applicability of HT9 cladding behavior models to transients lasting tens of hours. The FM-6 fuel pin was particularly suited for this test because it had a short plenum and high burnup. At end of life in EBR-II the plenum pressure was estimated to be $14.4 \mathrm{MPa}$ at $517^{\circ} \mathrm{C}$. This translates to a peak cladding hoop stress of about $115 \mathrm{MPa}$ at $650^{\circ} \mathrm{C}$.

The FPIN2 results given in Table 2 predicted significant cladding straining and cladding failure after only about 3 hours at $650^{\circ} \mathrm{C}$. These results are in obvious disagreement with the experimental data, especially given the fact that the cladding temperature in the plenum actually reached $670^{\circ} \mathrm{C}$ during the test. The source of this lack of agreement is evidently the strengthening of the cladding during long-time exposure. If this is the case, one would expect the LIFE-METAL predictions based on long-term creep behavior of HT9 to have given better agreement with the data.

The LIFE-MFTAL calculations reported in Table 2 are for the higher pin temperatures that were measured during the test. The predicted failure time under these conditions is about 22 hours, which is well into the second stage of the test. Although the pin survived for the full 36 hours, the LIFE-METAL result is within the expected scatter of the cladding rupture data. The peak cladding strain is also in reasonable agreement with the measurement. Furthermore, the predicted peak cladding strains after the 12 hour heating agree very well with the profilometry data obtained in the interim examination. The calculated incremental cladding strains at the fuel top and plenum were $0.30 \%$ and $0.31 \%$, respectively, versus the measured strains of $0.33 \%$ and $0.31 \%$, respectively.

\subsection{Conclusions}

Both the LIFE-METAL and FPIN2 fuel pin behavior codes provide valuable frameworks for investigating the behavior of metallic fuel pins for extended transient events. However, the analyses require a considerable extrapolation for each of the codes since LIFE-METAL has primarily been developed and validated to describe long-term irradiation performance, whereas FPIN2 has primarily been developed and validated to describe short-term transient behavior. Application of the codes to the pretest analyses of the Whole Pin Furnace tests is leading to a better understanding as to which models contained within the codes are, and are not, applicable to extended transient events. 
Some of the most important differences in the codes are the HT9 cladding deformation and rupture mocels. The results of the Whole Pin Furnace tests suggest that models based on tensile and transient burst data are applicable to the short-time tests (m:nutes) while the models based on creep data are applicable to the longer-lime tests (tens of hours). An effort is underway to model the transition between these two types of behavior so that the codes car cover the entire range of interest to the analysis of extended transients.

Other than the above considerations, the codes showed general agreement with the results of the WPF tests. A notable exception is the FM-4 test where neither code predicted a failure time within the expected range of uncertainty of the model parameters. It is postulated that the longer failure time in this test may have been caused by greater straining in the gas plenum than was predicted.

\section{References}

[1] Y. I. Chang, Nucl. Technology 88 (1989) 129.

[2] D. J. Hill, D. R. Pedersen and J. F. Marchaterre, Proc. of the 23d Intersociety Energy Conversion Engineering Conference (ASME, Denver, CO, 1988) p.473

[3] J. E. Cahalan, J. M. Kramer, J. F. Marchaterre, C. J. Mueller, D. R. Pedersen, R. H. Sevy, D. C. Wade and T. C. Y. Wei, Proc. International Topical Meeting on the Safety of Next Generation Power Reactors (ANS, Seattle, WA, 1988) p.103.

[4] R. C. Berglund, F. E. Tippets and L. N. Salerno, Proc. International Topical Meeting on the Safety of Next Generation Power Reactors (ANS, Seattle, WA, 1988) p.599.

[5] J. S. McDonald, Proc. International Topical Meeting on the Safety of Next Generation Power Reactors (ANS, Seattle, WA, 1988) p.606 
[6] J. M. Kramer and T. H. Bauer, Proc. 1990 International Fast Reactor Safety Meeting (ANS, Snowbird, UT, 1990) vol. IV, p.145.

[7] T. H. Bauer, G. R. Fenske and J. M. Kramer, Transactions of the 9th International Conference on Structural Mechanics in Reactor Technology (Lausanne, 1987) vol. C, p.31.

[8] A. B. Cohen, H. C. Tsai and L. A. Neimark, J. Nucl. Mater., in this volume.

[9] R. J. DiMelfi, E. E. Gruber, J. M. Kramer and T. H. Hughes, to appear in the Proceedings of the Symposium on Microstructures and Mechanical Properties of Aging Materials (TMS, Chicago, IL, 1992).

[10] N. S. Cannon, F. H. Huang and M. L. Hamilton, Effects of Radiation on Materials: 14th International Symposium, vol. II, ed. N. H. Packen, R. E. Stoller and A. S. Kumar (ASTMSTP 1046, Philadelphia, PA, 1991) p. 729.

[11] T. H. Bauer, A. E. Wright, W. R. Robinson, J. W. Holland and E. A. Rhodes, Nuclear Technology 92 (1990) 325.

[12] Y. Y. Liu, H.C. Tsai, D. A. Donahue, D. O. Pushis, F. E. Savoie, J. W. Holland, A. E. Wright, C. August, J. L. Bailey and D. Patterson, Proc. 1990 International Fast Reactor Safety Meeting (ANS, Snowbird, UT, 1990) vol. I, p.491.

[13] M. C. Billone, Y. Y. Liu, E. E. Gruber, T. H. Hughes and J. M. Kramer, Proc. ANS International Conference on Reliable Fuels for Liquid Metal Reactors (ANS, Tucson, AZ, 1986) p.5-77

[14] T. H. Hughes and J. M. Kramer, Proc. of the Conference on the Science and Technology of Fast Reactor Safety (BNES, Guernsey, UK, 1986) vol.2, p.427.

[15] Y. Y. Liu, H. Tsai, M. C. Billone, J. W. Holland and J. M. Kramer, J. Nucl. Mater., in this volume. 
Table 1

Key pin parameters and test conditions for Whole Pin Furnace tests

\begin{tabular}{ccccccc}
\hline Test No. & Fuel Type & Cladding Type & $\begin{array}{c}\text { Plenum } \\
\text { Fuel Vol. } \\
\text { Ratio }\end{array}$ & $\begin{array}{c}\text { Burnup } \\
(\mathrm{a} / \mathrm{o})\end{array}$ & $\begin{array}{c}\text { Test } \\
\text { Temp. } \\
\left({ }^{\circ} \mathrm{C}\right)\end{array}$ & $\begin{array}{c}\text { Test Duration } \\
\text { (min.) }\end{array}$ \\
\hline FM-1 & U-10Zr & HT9 & 1.0 & 3.0 & 820 & 67 \\
FM-2 & U-19Pu-10Zr & HT9 & 1.0 & 3.0 & 820 & 112 \\
FM-3 & U-26Pu-10Zr & HT9 & 1.4 & 2.2 & 820 & 146 \\
FM-4 & U-19Pu-10Zr & HT9 & 1.5 & 11.4 & 770 & 68 \\
FM-5 & U-19Pu-10Zr & HT9 & 1.5 & 11.4 & $\begin{array}{c}\text { ramp to } \\
780 ; \text { cool }\end{array}$ & 3 \\
FM-6 & U-19Pu-10Zr & HT9 & 1.0 & 11.3 & $650-670$ & 2160 \\
\hline
\end{tabular}




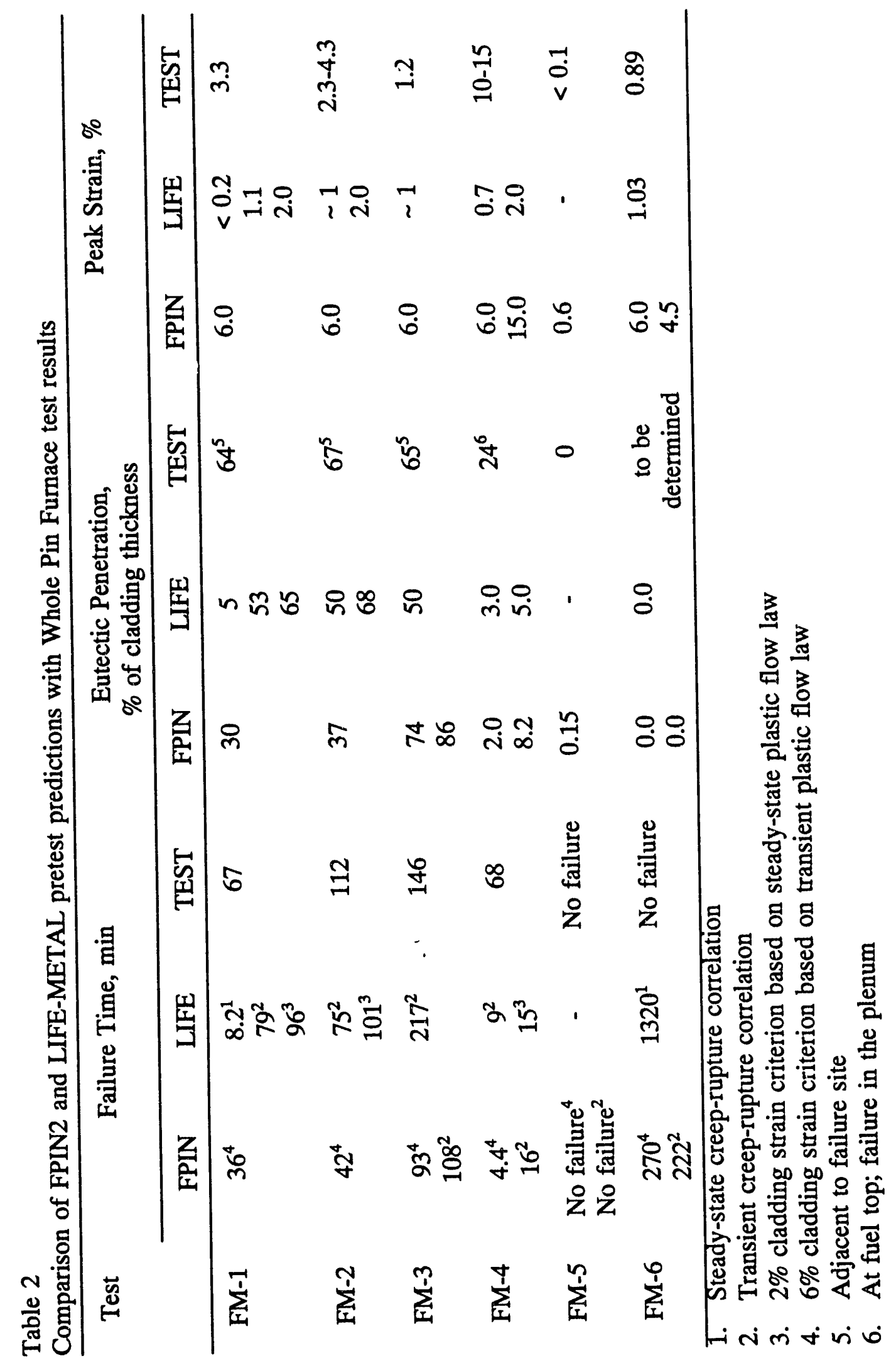




\section{List of Figures}

Fig. 1. Representative Peak Cladding Temperature Histories for Various Accident Transients in Metal-fueled Fast Reactors.

Fig. 2. Transient Cladding FCTT Burst Data and Long-term Creep-rupture Data Normaiized Using the Dorn Parameter.

Fig. 3. Comparison of the Measured Temperature Near the Top of the Fuel Column in the FM-5 Test with the Calculated Peak Cladding Temperature History for the EBR-II UN-1 Loss-of-Flow Event. 


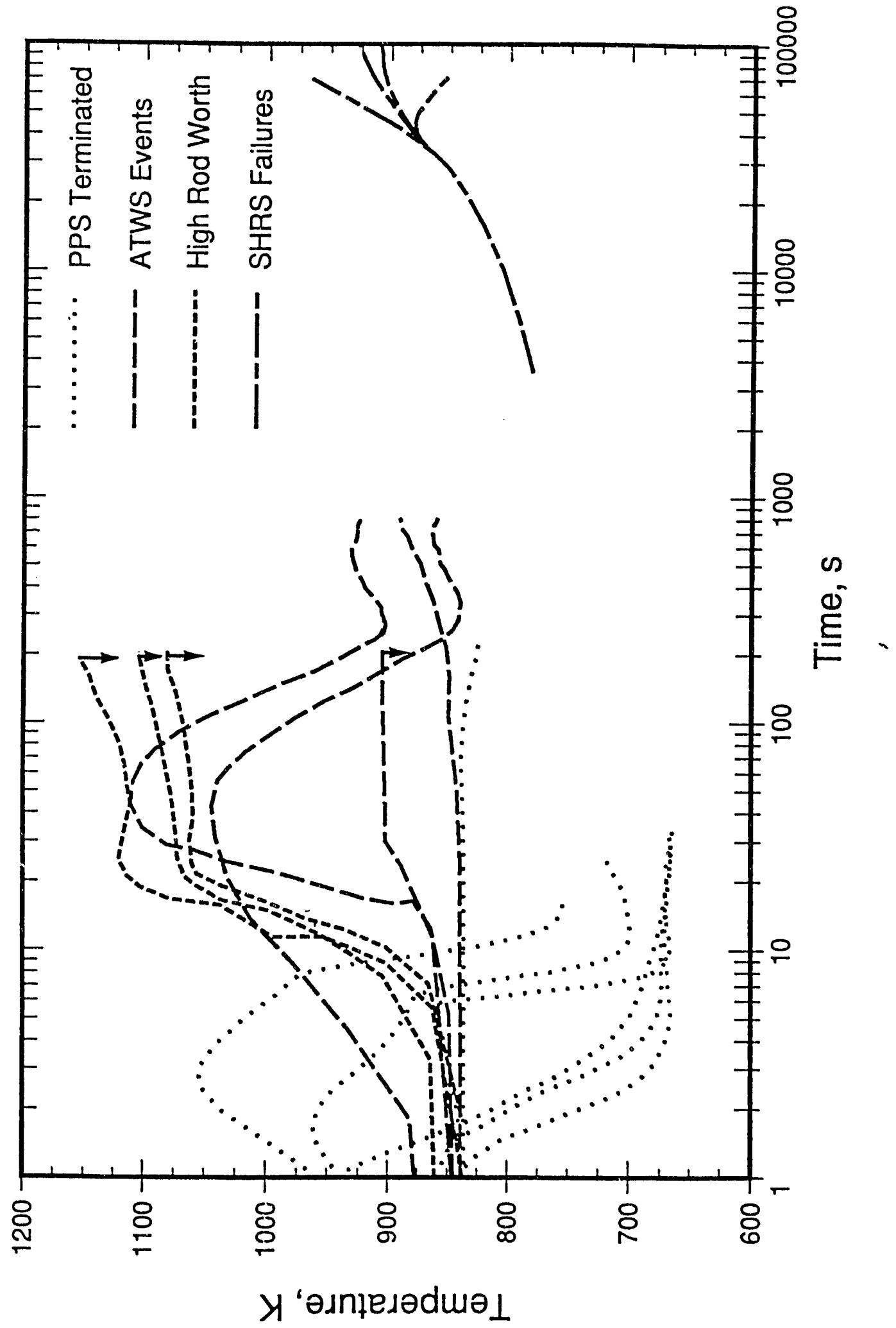




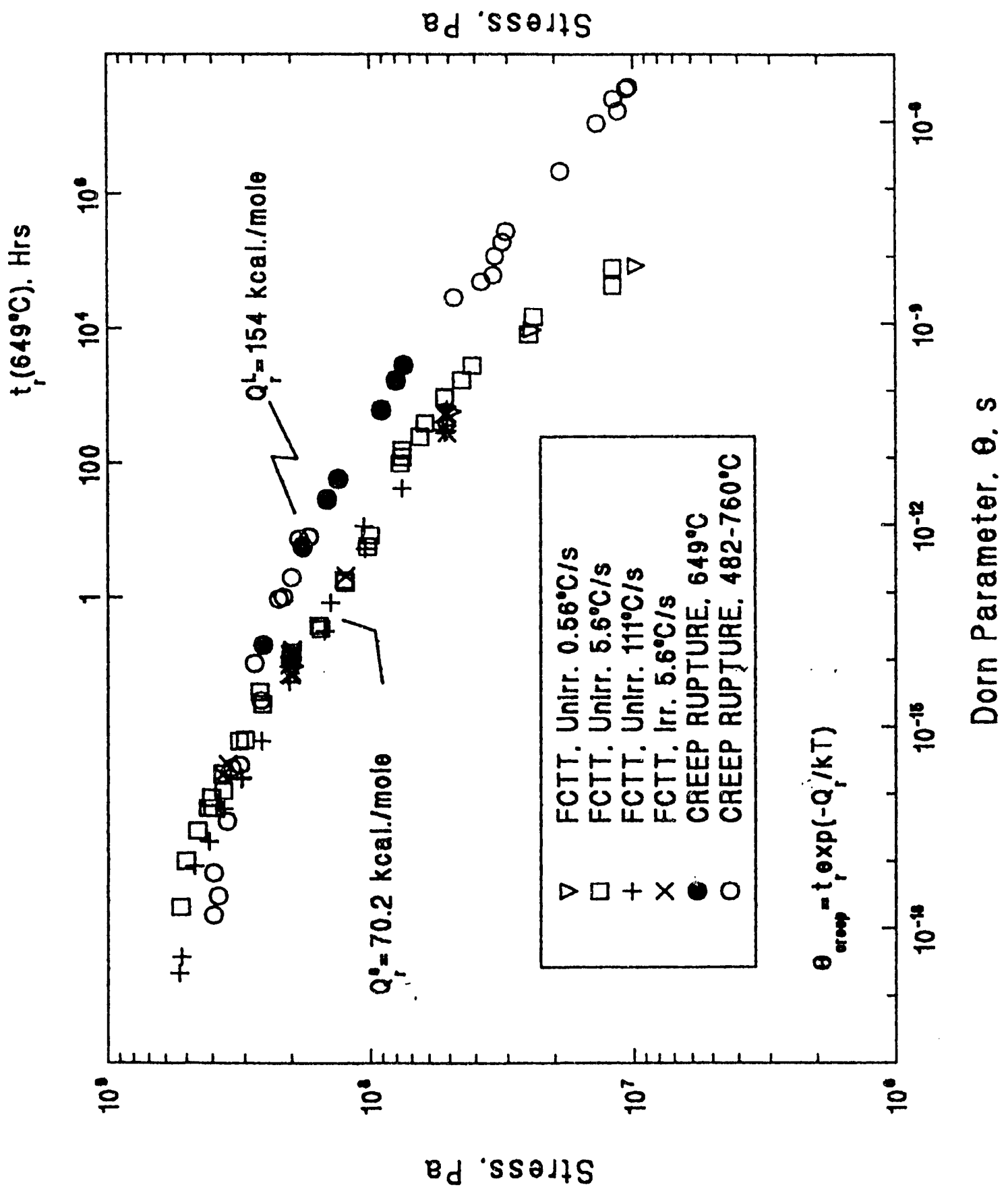




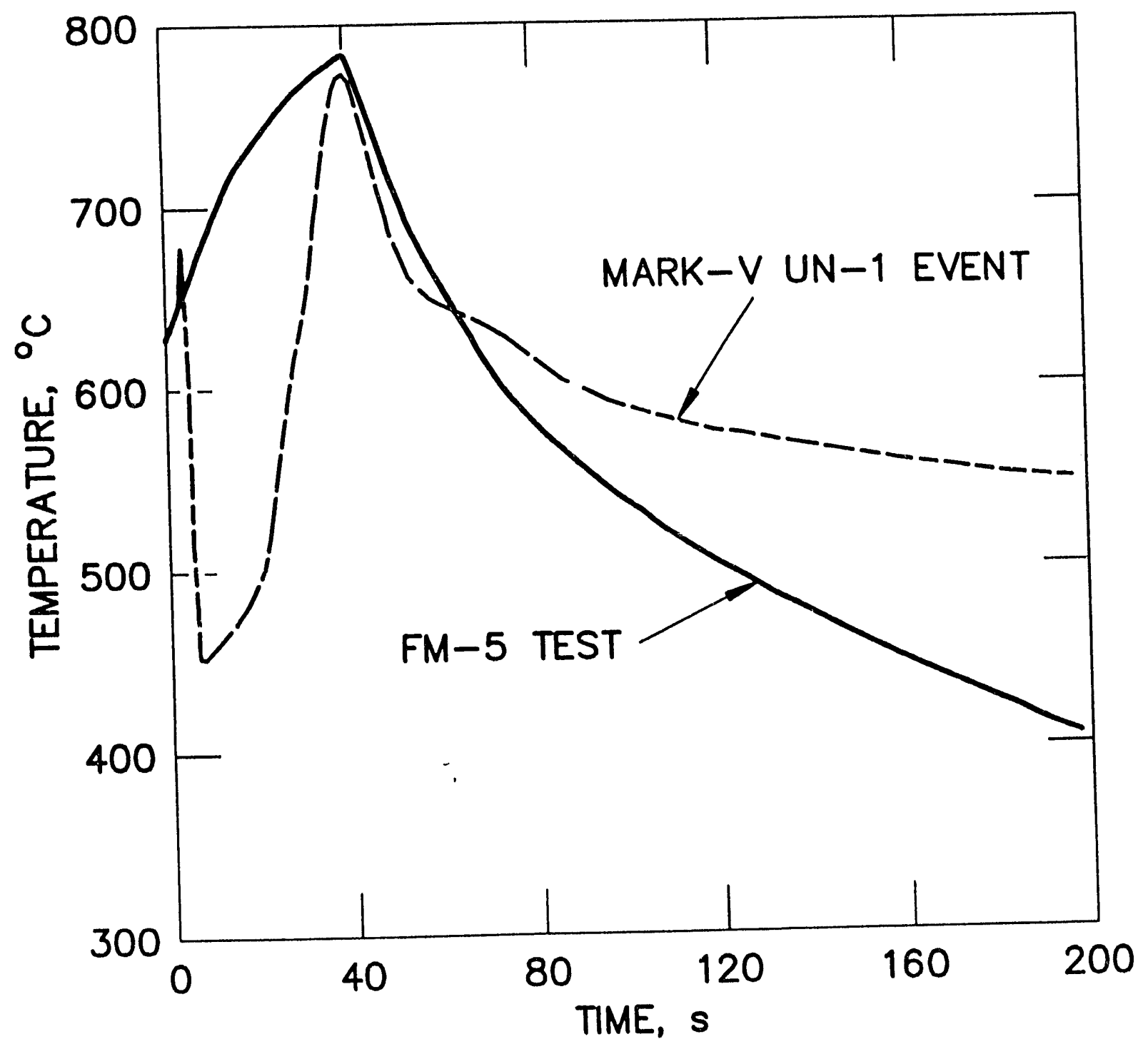

Fig. 3 

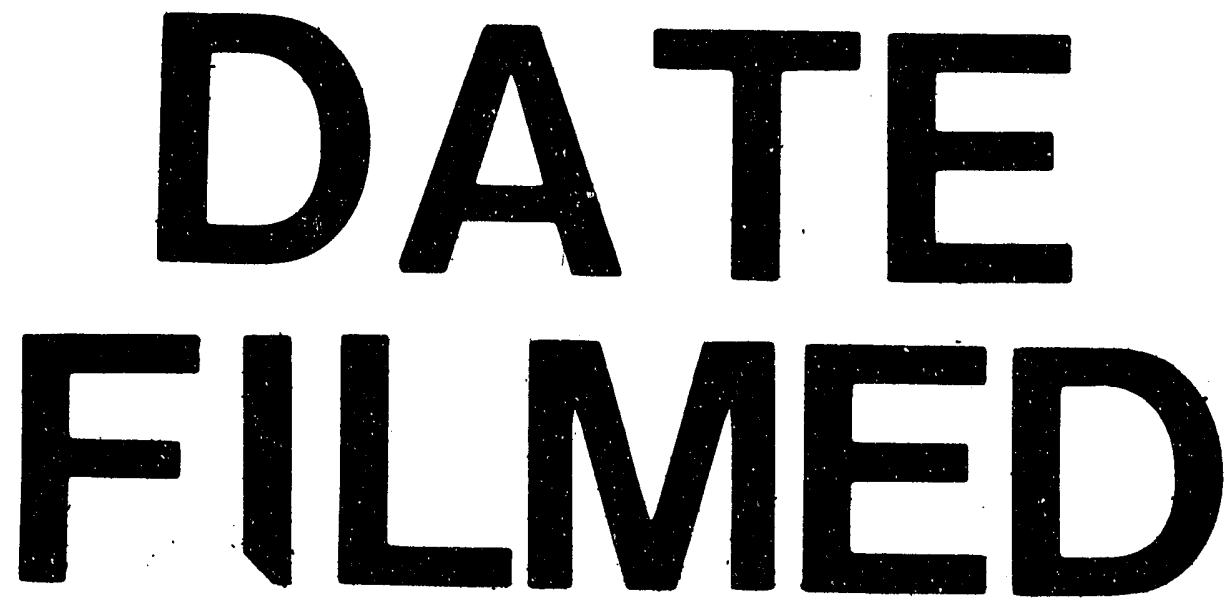

$01 / 21 / 93$ 
